\title{
Hepatitis B virus upregulates cellular inhibitor of apoptosis protein 2 expression via the PI3K/AKT/NF-кB signaling pathway in liver cancer
}

\author{
JIANPING LIAN ${ }^{1,2}$, YUANHUA ZOU ${ }^{3}$, LING HUANG $^{2}$, HAO CHENG $^{4}$, \\ KAI HUANG ${ }^{5}$, JUNQUAN ZENG ${ }^{3}$ and LONGHUA CHEN ${ }^{1}$
}

\begin{abstract}
${ }^{1}$ Department of Radiation Oncology, Nanfang Hospital of Southern Medical University, Guangzhou, Guangdong 510515; Departments of ${ }^{2}$ Oncology and ${ }^{3}$ Rehabilitation, The Affiliated Hospital of Jinggangshan University, Ji'an, Jiangxi 343000; ${ }^{4}$ Department of Nasopharyngeal Carcinoma, The First People's Hospital of Chenzhou, Southern Medical University, Chenzhou, Hunan 423000; ${ }^{5}$ Department of Gastrointestinal Surgery, Jiangxi Provincial Cancer Hospital, Nanchang, Jiangxi 330029, P.R. China
\end{abstract}

Received July 13, 2019; Accepted November 1, 2019

DOI: $10.3892 / \mathrm{ol} .2020 .11267$

\begin{abstract}
Activation of antiapoptotic genes has been indicated as one of the factors that contributes to hepatitis B virus (HBV) infection-induced liver cancer. The cellular inhibitor of apoptosis protein 2 (cIAP2), a member of the IAP family, is upregulated in various types of cancer and serves as a potential treatment target. However, to the best of our knowledge, the importance of cIAP2 in HBV-induced liver cancer has not been investigated. In the present study, cIAP2 expression in liver cells in response to HBV infection and the underlying mechanism involved was investigated. Western blot analysis of clinical liver samples showed that higher cIAP2 expression was detected in HBV-positive non-cancerous tissue compared with that in $\mathrm{HBV}$-negative non-cancerous tissue, and the expression was further increased in HBV-positive liver cancer tissue. Reverse transcription-quantitative PCR and western blot experiments performed on two liver cell lines also confirmed that cIAP2 expression was increased upon HBV infection at both the mRNA and protein levels. Promoter analysis revealed that HBV could activate cIAP2 promoter in an infection dose-dependent manner, and this activation involved a NF- $\mathrm{B}$-binding site in the cIAP2 promoter. Further analysis demonstrated that $\mathrm{HBV}$ enhanced $\mathrm{NF}-\kappa \mathrm{B}$ phosphorylation and nuclear translocation via the PI3K/AKT signaling pathway, leading to the binding and activation of cIAP2 promoter. The present data demonstrates that HBV-infection induces cIAP2 expression in the liver by activation of the PI3K/AKT/NF- $\mathrm{BB}$
\end{abstract}

Correspondence to: Dr Longhua Chen, Department of Radiation Oncology, Nanfang Hospital of Southern Medical University, 1838 Guangzhou N Avenue, Guangzhou, Guangdong 510515, P.R. China E-mail: ds_clh@hotmail.com

Key words: hepatitis B virus, liver cancer, cellular inhibitor of apoptosis protein 2 , signaling pathway signaling pathway through promoting the binding of $\mathrm{NF}-\kappa \mathrm{B}$ to cIAP2 promoter, which may lead to carcinogenesis. The findings from the present study provide more information for understanding HBV-induced liver cancer and also offer a potential target for treatment or diagnosis of this disease.

\section{Introduction}

Liver cancer is the second leading cause of cancer worldwide, with liver cancer representing $\sim 90 \%$ of all primary liver cancer cases in 2016 (1-3). A number of risk factors have been identified for liver cancer, and among these factors, chronic hepatitis B virus (HBV) infection accounts for $>50 \%$ cases of liver cancer worldwide in 2016 (4-6). Given that HBV is one of the most common infections in the world, with 257 million people living with chronic $\mathrm{HBV}$, and that an estimated $20-30 \%$ of chronically HBV infections in adults would lead to liver cancer in 2016, the number of HBV-associated liver cancer cases is vast $(7,8)$. Consequently, understanding the pathogenesis of HBV infection-induced liver cancer is of great importance for the development of strategies for liver cancer diagnosis and treatment.

Numerous possible mechanisms have been proposed underlying HBV infection-induced liver cancer so far, which can be categorized into direct and indirect mechanisms. Directly, HBV high level replication and genomic integration may cause chromosomal alterations, including chromosomal instability due to viral genomic integration occurring in random locations of any chromosome, and increase the risk of cancer gene activation (9-12). In addition, HBV encodes a few oncogenesis genes, such as $\mathrm{HBx}$ and preS2/S, which directly induces carcinogenesis (13-16). Indirectly, HBV infection causes long-term inflammation in the liver, leading to increased hepatocyte proliferation, hepatic fibrosis and cirrhosis $(14,17)$. Furthermore, HBV can also activate a range of antiapoptotic host proteins, such as Bcl-2 and survivin, which promote carcinogenesis $(18,19)$. However, it seems that none of these mechanisms can explain all the clinical features observed in 
HBV-induced liver cancer, for example liver cancer can occur in the absence of inflammation $(10,20,21)$, and HBV integration is random and rarely leads to direct oncogene activation (14). Therefore, the mechanism underlying HBV infection-induced liver cancer is multifaceted and more possible mechanisms are still to be identified.

The cellular inhibitor of apoptosis protein 2 (cIAP2), a member of the IAP family, can inhibit cell apoptosis via inhibition of caspase activity (22). cIAP2 expression is significantly increased in a variety of human cancer types, including colorectal cancer, lung cancer and prostate cancer, and high expression of this protein is associated with poor outcome of these cancers (22-24). In colorectal cancer, cIAP2 has previously been reported to be a valuable therapeutic target, as downregulation of this protein efficiently enhances cancer cell apoptosis (25). In liver cancer, however, little is known about the expression and impact of cIAP2 on HBV-induced liver cancer pathogenesis. In the present study, the expression of cIAP2 was initially investigated in liver cancer tissue samples and adjacent non-cancerous tissue samples with or without $\mathrm{HBV}$ infection, and then the impact of HBV infection on cIAP2 expression and underlying mechanism was explored. The findings of the current study provide further understanding on the pathogenesis of HBV-induced liver cancer and could also be valuable for the development of strategies for liver cancer diagnosis and treatment.

\section{Materials and methods}

Patient samples, cell lines and virus. Liver and blood samples were obtained from 8 patients, including 4 male and 4 female patients (range, 46-52 years; mean, 49 years) with liver cancer who underwent resection at the Affiliated Hospital of Jinggangshan University (Jiangxi, China) between November 2017 and May 2018. Cancerous (CT) and non-cancerous tissues (NCT) were then separated and frozen in $-80^{\circ} \mathrm{C}$ until required. The NCT samples were collected from at least $0.5 \mathrm{~cm}$ away from CT samples. Blood samples were used for HSV-2 infection determination using ELISA (HerpeSelect ${ }^{\circledR} 1$ and 2 Immunoblot IgG; Focus Diagnostics, Inc.) and PCR (artus HSV-1/2 PCR Kits; Qiagen China Co., Ltd.), as previously described (26). All protocols involving human samples were reviewed and approved by the Ethical Review Board at the Affiliated Hospital of Jinggangshan University (Jiangxi, China; ref. JGSU-20170071), and written informed consent was provided from all the participating patients.

The normal liver cell line, THLE-3, the non-HBV expressing human liver cancer cell line HepG2 and persistent HBV-expressing liver cancer cell line, HepG2.2.15 were all purchased from the American Type Culture Collection and cultured in DMEM (Sigma-Aldrich; Merck KGaA) supplemented with 10\% FBS (Gibco; Thermo Fisher Scientific, Inc.) and penicillin and streptomycin (both at $100 \mathrm{U} / \mathrm{ml}$; Gibco; Thermo Fisher Scientific, Inc.) at $37^{\circ} \mathrm{C}$ with $5 \% \mathrm{CO}_{2}$.

HBV used in the present study was harvested from HepG2.2.15 cells as previously described (27). In brief, cell culture media were first filtered through a $0.45-\mu \mathrm{m}$ filter, and then precipitated using a PEG-it Virus Precipitation Solution (System Biosciences, LLC) according to the manufacturer's instructions. In brief, virus-containing medium was first mixed with cold PEG-it Virus Precipitation Solution at the ratio of $4: 1$ and incubated into the mixture overnight at $4^{\circ} \mathrm{C}$. Following incubation, the virus and PEG-it Virus Precipitation Solution mixture was centrifuged at $1,500 \mathrm{x}$ g for $30 \mathrm{~min}$ at $4^{\circ} \mathrm{C}$. Following centrifugation, all traces of fluid were removed by aspiration and pelleted viruses were washed with PBS twice and concentrated using Amicon $100 \mathrm{kD}$ ultracentrifugal tubes (EMD Millipore; Merck KGaA). Finally, viruses were resuspended in PBS containing 25\% FBS (Gibco; Thermo Fisher Scientific, Inc.), aliquoted and stored at $-80^{\circ} \mathrm{C}$ until required. HBV titer was assessed using quantitative PCR and quantified as genome equivalent $/ \mathrm{ml}(\mathrm{GEq} / \mathrm{ml})$, as previously described (28).

Plasmids. pGL3-Basic (Promega Corporation), a vector with a firefly luciferase gene under the control of a promoter of interest to be cloned in by the user, was used to construct all plasmids containing full length, truncated or mutated cIAP2 promoters and NF- $\mathrm{KB}$ promoter. Full length cIAP2 promoter, $(-2,000 /+55)$ cIAP2-Luc, and its truncations, $(-1,000 /+55)$ cIAP2-Luc, (-500/+55) cIAP2-Luc, (-250/+55) cIAP2-Luc and $(-100 /+55)$ cIAP2-Luc, as well as full length NF-kB promoter, NF- $\kappa B-L u c$, sequences were synthesized by GenScript Biotech Corporation and subcloned into pGL3-Basic using the NEBuilder HiFi DNA Assembly master mix (New England Biolabs), according to the manufacturer's instructions. Site-directed mutations to the $(-2,000 /+55)$ cIAP2-Luc plasmid was introduced using the QuikChange II Site-Directed Mutagenesis kit (Agilent Technologies) according to the manufacturer's instructions. For activator protein 1 (AP1) mutant (MUT), the AP1 sequence was mutated from 5'-TTT TGGGTCATGG-3' to 5'-TTTTGGGTCGCGG-3'. There are $3 \mathrm{NF}-\kappa \mathrm{B}$ binding sites selected for this study in the cIAP2 promoter: NF- $\kappa B^{*}, N F-\kappa B^{* *}$ and NF- $\kappa B^{* * *}$. For NF- $\kappa B^{*}$ MUT, $N F-\kappa B^{* *}$ MUT and NF- $\kappa B^{* * *}$ MUT, NF- ${ }^{*} B$ sequences were mutated from 5'-GGAAATCCCC-3' to 5'-GGAAATAGC C-3', from 5'-TGGGTTTGCC-3' to 5-'CTCGTTTGCC-3' and from 5'-TGGAGTTCCC-3' to 5'-TGGAGTTAAC-3', respectively. For interferon regulatory factor-1 (IRF-1) MUT, the IFR-1 sequence was mutated from 5'-TAAAAGGAAAG-3' to 5'-TAACAGGAGAG-5'.

Transfection and luciferase reporter gene activity assay. Transfection and luciferase reporter gene activity assay was performed as previously described with modifications (26). In brief, THLE-3 cells were transfected with promoter constructs together with control plasmid pRL-RK (Promega Corporation) using Lipofectamine $2000^{\circledR}$ (Thermo Fisher Scientific, Inc.) according to the manufacturer's instructions. The medium was changed, and the cells were subsequently infected with or without $\mathrm{HBV}$ at $100 \mathrm{GEq} / \mathrm{cell}$ or ascendant doses of $\mathrm{HBV}(0$, $50,100,200$ and $500 \mathrm{GEq} / \mathrm{cell}$ ) for $1 \mathrm{~h}$ at $37^{\circ} \mathrm{C}, 4-6 \mathrm{~h}$ after transfection. Fresh complete medium was added and the cells were cultured at $37^{\circ} \mathrm{C}$ with $5 \% \mathrm{CO}_{2}$ for another $24 \mathrm{~h}$. After which time, cells were lysed with Luciferase Cell Culture Lysis buffer (Promega Corporation) and firefly luciferase activity and Renilla luciferase activity were measured using the Dual-Luciferase ${ }^{\circledR}$ Reporter Assay System (Promega Corporation), according to the manufacturer's protocol. The 
transfection efficiency was normalized to the Renilla luciferase activity. For small interfering RNA (siRNA)-mediated knockdown of p65 or AKT, siRNA targeting p65 (cat. no. sc-29410), AKT (cat. no. sc-43609) or control siRNA (cat. no. sc-37007) at a final concentration of $100 \mathrm{nM}$ was introduced into cells using siRNA Transfection Reagent (all from Santa Cruz Biotechnology, Inc.) $24 \mathrm{~h}$ before plasmid transfection. For signaling pathway inhibition, specific inhibitors against $\mathrm{NF}-\kappa \mathrm{B}$ (Celastrol; $300 \mathrm{nM}$ ), MAPKK (PD98059; $10 \mu \mathrm{M}$ ), PI3K (LY294002; $50 \mu \mathrm{M}$ ) or p38 (SB203580; $10 \mu \mathrm{M}$ ) was added into the medium after virus infection and remained throughout the culture. All inhibitors were purchased from InvivoGen and used according to the manufacturer's instructions.

RNA extraction and reverse transcription-quantitative $P C R$ (RT-qPCR). Total RNA was extracted from THLE-3, HepG2 and HepG2.215 cells using the RNeasy Mini kit (Qiagen, Inc.) and reverse-transcribed into cDNA using the ProtoScript ${ }^{\circledR}$ II First Strand cDNA Synthesis kit (New England Biolabs, Inc.), according to the manufacturer's instructions. The cDNA synthesis reaction mix was first incubated at $42^{\circ} \mathrm{C}$ for $1 \mathrm{~h}$ for cDNA synthesis and then the enzyme was inactivated at $80^{\circ} \mathrm{C}$ for $5 \mathrm{~min}$. Target gene mRNA level was subsequently determined using SYBRGreen qPCR using the SsoAdvanced Universal SYBR-Green Supermix on a Bio-Rad CFX Connect platform (both Bio-Rad Laboratories, Inc.). The thermocycling conditions were as follows: Polymerase activation and DNA denaturation $\left(95^{\circ} \mathrm{C}, 1 \mathrm{~min}\right) ; 40$ cycles of denaturation $\left(95^{\circ} \mathrm{C}, 10 \mathrm{sec}\right)$ and annealing/extension $\left(60^{\circ} \mathrm{C}, 30 \mathrm{sec}\right)$, and then followed by melt-curve analysis $\left(65-95^{\circ} \mathrm{C}\right.$ with $0.5^{\circ} \mathrm{C}$ increment $2-5 \mathrm{sec} / \mathrm{step})$. The following primers were used: cIAP2 forward, 5'-GATGTTTCAGATCTACCAGTG-3' and reverse, 5'-GAAATGTACGAACTGTACCCT-3'; NF- $\kappa$ B (p65) forward, 5'-ATGGCTTCTATGAGGCTGAG-3' and reverse, 5'-GTTGTTGTTGGTCTGGATGC-3'; internal control $\beta$-actin forward, 5'-AAGCAGGAGTATGACGAGTCCG-3', and reverse, 5'-GCCTTCATACATCTCAAGTTGG-3'. Target gene mRNA level was quantified using the $2^{-\Delta \Delta \mathrm{Cq}}$ method (29).

Isolation of cell cytoplasmic and nuclearfractions. The cytoplasmic and nuclear fractions were isolated from THLE-3 cells using a Cell Fractionation kit (cat. no. ab109718; Abcam) according to the manufacturer's instructions. In brief, cells were first harvested by trypsinization and resuspended in buffer $\mathrm{A}$, and then an equal volume of buffer $\mathrm{B}$ was added and mixed for $7 \mathrm{~min}$ at room temperature. After centrifugation at $5,000 \mathrm{x}$ for $1 \mathrm{~min}$ at $4^{\circ} \mathrm{C}$, the supernatant (cytoplasmic fraction) was removed to a new tube, while the pellet was further incubated with buffer $\mathrm{C}$ for $10 \mathrm{~min}$ at room temperature with constant mixing. Following centrifugation at $5,000 \mathrm{x} \mathrm{g}$ for $1 \mathrm{~min}$ at $4^{\circ} \mathrm{C}$, the supernatant (nuclear fraction) was transferred to a new tube. All fractionized samples were either stored at $-80^{\circ} \mathrm{C}$ or used directly for downstream experiments.

Western blot analysis. Western blot was performed as previously described with modifications $(30,31)$. Depending on the experiment, CT and NCT tissue samples, THLE-3, HepG2 and HepG2.215 cells with or without transfection, and cytoplasmic and nuclear fractions were used for western blot analysis. CT and NCT tissue samples were first homogenized in PBS supplemented with protease inhibitor cocktail (Roche Diagnostics), and then centrifuged at $14,000 \times \mathrm{g}$ for $10 \mathrm{~min}$ at $4^{\circ} \mathrm{C}$, and then supernatants were transferred into new tubes, mixed with $4 \mathrm{x}$ SDS-PAGE loading buffer. THLE-3, HepG2 and HepG2.215 cells with or without transfection were first harvested using non-enzymatic cell dissociation buffer (Sigma-Aldrich; Merck $\mathrm{KGaA}$ ), washed with PBS and then lysed using Pierce immunoprecipitation (IP)/lysis buffer (Thermo Fisher Scientific, Inc.) supplemented with protease inhibitor cocktail (Roche Diagnostics). Centrifugation $\left(14,000 \mathrm{x} \mathrm{g}, 10 \mathrm{~min}\right.$ at $\left.4^{\circ} \mathrm{C}\right)$ cleared protein samples were then mixed with SDS-PAGE loading buffer. Cell cytoplasmic and nuclear fractions were directly mixed with 4X SDS-PAGE loading buffer and used for SDS-PAGE. All prepared samples were separated by $12 \%$ SDS-PAGE and transferred onto PVDF membranes. After blocking with 5\% skimmed milk for $1 \mathrm{~h}$ at room temperature, the membrane was sequentially incubated with primary antibodies and horseradish peroxidase (HRP)-conjugated secondary antibodies, overnight at $4^{\circ} \mathrm{C}$ and for $1 \mathrm{~h}$ at room temperature, respectively. After extensive washes with PBS-0.1\% Tween-20, the membrane was visualized with an enhanced chemiluminescence substrate (EMD Millipore) under a charge-coupled device camera (Bio-Rad Laboratories, Inc.). The following primary antibodies were used: Rabbit anti-cIAP2 (1:1,000 dilution; cat. no. ab23423; Abcam), mouse anti- $\beta$-actin (1:1,000 dilution; cat. no. sc-47778; Santa Cruz Biotechnology, Inc.), rabbit anti-NF- $\kappa$ B p65 (1:1,000 dilution; cat. no. 8242; Cell Signaling Technology, Inc.), rabbit anti-phosphorylated (p)-NF- $\mathrm{B}$ p65 (1:1,000 dilution; cat. no. 3033; Cell Signaling Technology, Inc.), mouse anti-PI3K (1:1,000 dilution; cat. no. 60225-1-Ig; ProteinTech Group, Inc.), rabbit anti-AKT (1:1,000 dilution; cat. no. 9272; Cell Signaling Technology, Inc.), rabbit anti-p-AKT (1:1,000 dilution; cat. no. 9271; Cell Signaling Technology, Inc.) and mouse anti-proliferating cell nuclear antigen (1:1,000 dilution; cat. no. sc-56; Santa Cruz Biotechnology, Inc.). The following secondary antibodies were used: HRP-conjugated goat anti-mouse IgG (H+L) (1:30,000 dilution; cat. no. SA00001-1) and HRP-conjugated goat anti-rabbit IgG $(\mathrm{H}+\mathrm{L})(1: 30,000$ dilution; cat. no. SA00001-2; both ProteinTech Group, Inc.). To quantify band intensity, ImageJ (version 1.51j8; National Institutes of Health) was used.

Chromatin (Ch)IP assay. The ChIP assay was performed using a Pierce Magnetic ChIP kit (Thermo Fisher Scientific, Inc.) according to the manufacturer's instructions. In brief, THLE-3 cells mock-infected with medium or infected with HBV were first washed with PBS and then crosslinked with ChIP grade $1 \%$ formaldehyde (Thermo Fisher Scientific, Inc.). Following crosslinking, cells were lysed and digested with membrane extraction buffer and micrococcal nuclease, respectively. The chromatin smear was then obtained using sonication $(3 \times 20 \mathrm{sec}$ pulses at $3 \mathrm{~W}$ power on ice with $20 \mathrm{sec}$ incubation on ice between pulses), and subsequently incubated with $5 \mu \mathrm{g}$ of either control Ig or ChIP grade anti-p65 antibody (both control Ig and anti-p65 were from the same ChIP kit; cat. no. 17-10060; Sigma-Aldrich; Merck KGaA) overnight at $4^{\circ} \mathrm{C}$. Following incubation, magnetic beads were added into the mixture and incubated for a further $2 \mathrm{~h}$ at $4^{\circ} \mathrm{C}$. 


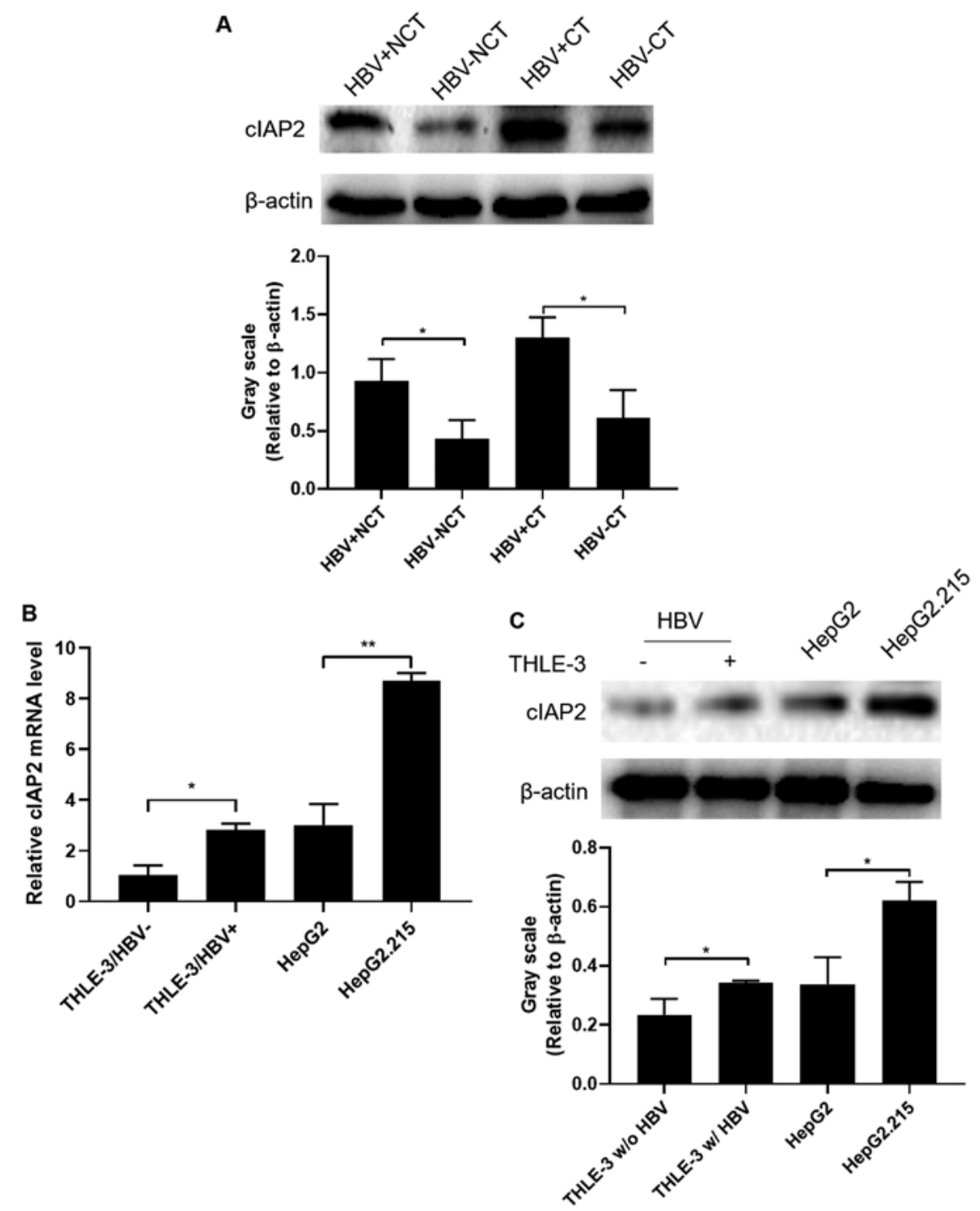

Figure 1. cIAP2 expression is upregulated in HBV-infected liver CT and NCT and cell lines. (A) cIAP2 protein levels in liver samples from CT and adjacent NCT were obtained from patients with liver cancer and who were either $\mathrm{HBV}^{+}$or $\mathrm{HBV}^{-}$were determined using western blot analysis. (B) $\mathrm{mRNA}$ and (C) protein expression levels of cIAP2 in the normal liver cell line THLE-3 with or without HBV infection, the non-HBV expressing human liver cancer cell line HepG2 and the persistent HBV-expressing liver cancer cell line HepG2.215 using reverse transcription-quantitative PCR and western blot analysis. Data are presented as the mean \pm standard deviation of three independent experiments. For western blot analysis, one representative result out of three is shown. "P<0.05; ${ }^{* *} \mathrm{P}<0.01$. cIAP2, cellular inhibitor of apoptosis protein 2; HBV, hepatitis B virus; CT, cancerous tissue; NCT, non-cancerous tissue.

After extensive washes with PBS-0.05\% Tween-20, DNA was eluted from magnetic beads with elution buffer. Finally, a PCR amplifying the cIAP2 promoter was performed using Q5 ${ }^{\circledR}$ High-Fidelity DNA Polymerase (New England BioLabs. Inc) with the following primers: Forward, 5'-CCCGAGTGGGTT TGCCAG-3' and reverse, 5'-TTTTAAATGCGTCACCCA AATCCCC-3'. The thermocycling conditions were as follows: Initial denaturation, $98^{\circ} \mathrm{C}, 30 \mathrm{sec} ; 35$ of cycles of denaturation $\left(98^{\circ} \mathrm{C}, 10 \mathrm{sec}\right)$, annealing $\left(55^{\circ} \mathrm{C}, 10 \mathrm{sec}\right)$ and elongation $\left(72^{\circ} \mathrm{C}\right.$, $30 \mathrm{sec})$; and final extension $\left(72^{\circ} \mathrm{C}, 2 \mathrm{~min}\right)$.

Statistical analysis. All experiments were repeated three times, independently. Data are expressed as mean \pm standard deviation, and all statistical analyses were performed using GraphPad Prism v8.1.2 (GraphPad Software, Inc.). Unpaired Student's t-test and one-way ANOVA with Student-Newman-Keuls post hoc test were used for comparisons between two groups or more than three groups, respectively. $\mathrm{P}<0.05$ was considered to indicate a statistically significant difference.

\section{Results}

cIAP2 expression is increased in $H B V$-infected liver tissue and liver cell lines. To determine cIAP2 expression in liver tissues in relation to $\mathrm{HBV}$ infection and liver cancer, liver samples from CT and adjacent NCT were obtained from patients with liver cancer and who were either $\mathrm{HBV}$-positive $\left(\mathrm{HBV}^{+}, 2\right.$ male and 2 female) or -negative ( $\mathrm{HBV}^{-}, 2$ male and 2 female), and had undergone surgery, and cIAP2 expression was determined using western blot analysis. As presented in Fig. 1A, cIAP2 expression in $\mathrm{HBV}^{+} \mathrm{NCT}$ was significantly increased compared with $\mathrm{HBV}^{-} \mathrm{NCT}$ samples, while the expression of cIAP2 in $\mathrm{HBV}^{+} \mathrm{CT}$ was further increased compared with $\mathrm{HBV}^{-} \mathrm{CT}$ samples $(\mathrm{P}<0.05)$. These data indicate that HBV infection could increase cIAP2 expression in liver tissue and 
A



C

-360 ATTGACCTTTTCCAGGCAGGCTAAGCAATGATCGTCCTCTCTATATGGGT

-310 TGTTATCAAGATTTCCTCTGACCCACGAGCAATGAAGCAAATGTCTTTGC

-260 AGTAAATGCCGCGAAGATATGCCACGGTTAAGAGTCATGCTITTGGGTC

-210 AT $\overline{\text { GGAAATCCCCGAGTGGTTTGCCAGGCCACTGATTAAGAGGAAGTG }}$

NF-KB***

-160 TGTGTGGTTATTACCGCTGGAGTTCCCCTAAGTCCTAAAAGGAAAGCAC

-110 CAGTGCACATGCAAACCACTGGGAGGAGTGCGGAACGCCTGGTACAG

TATA boX

-60 ATAGgGgtgGgGATtTGgGtGACGCA TTtAAAAGACAGCGTGAGACTC

10 GCGCCCTCCGGCACGGAAAAGG Transcription start site

GCCAGGCGACAGGTGTCGCTTGAAA
B



D

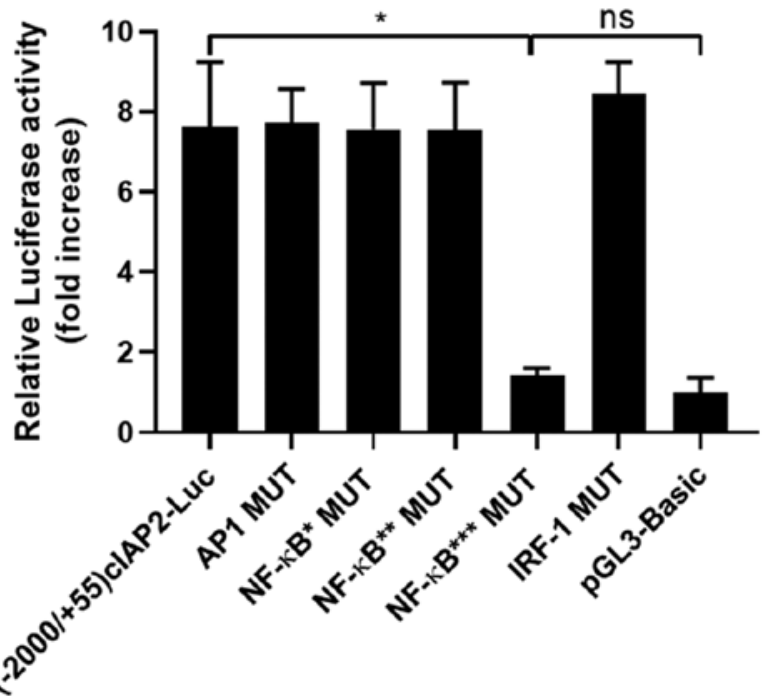

Figure 2. A NF-kB binding site in cIAP2 promoter is essential for HBV-induced cIAP2 promoter transactivation. (A) THLE-3 cells transfected with (-2,000/+55) cIAP2-Luc or pGL3-Basic and then infected with increasing doses of HBV. (B) THLE-3 cells transfected with serially truncated cIAP promoter constructs and then infected with $100 \mathrm{GEq} / \mathrm{cell}$ of HBV. Cells were lysed, and luciferase activity was measured $24 \mathrm{~h}$ later. (C) Predicted transcription factor binding sites within cIAP2 promoter sequence. The following transcription factor binding sites were detected in this region: 2 NFAT, 2 AP1, 3 NF-kB, 1 IRF-1 and 1 TATA box. Transcription start site is also indicated. (D) THLE-3 cells transfected with wild type or mutated (-2,000/+55)cIAP2-Luc (namely, AP1 MUT, NF-kB ${ }^{*}$ MUT, NF-kB B $^{* *}$ MUT, NF- $\mathrm{KB}^{* * *}$ MUT and IRF-1 MUT or pGL3-Basic were infected with $100 \mathrm{GEq} / \mathrm{cell}$ of HBV. Cells were lysed, and luciferase activity was measured $24 \mathrm{~h}$ later. Data are presented as the mean \pm standard deviation of three independent experiments. ${ }^{*} \mathrm{P}<0.05 .{ }^{* *} \mathrm{P}<0.01$. ${ }^{* * *} \mathrm{P}<0.001$. ns, not statistically significant; cIAP2, cellular inhibitor of apoptosis protein 2; HBV, hepatitis B virus; NFAT, nuclear factor of activated T-cells; AP1, activator protein 1; IRF-1, interferon regulatory factor-1; MUT, mutant; GEq, genome equivalent.

the persistent high expression of cIAP2 induced by HBV infection may have promoted liver cancer carcinogenesis.

To determine if this HBV infection-induced cIAP2 expression could also be observed in liver cell lines, the normal liver cell line, THLE-3 with or without HBV infection, the non-HBV expressing human liver cancer cell line, HepG2 and the persistent HBV-expressing liver cancer cell line, HepG2.2.15 were analyzed to determine the cIAP2 expression at both the mRNA and protein level. The data demonstrated that cIAP2 expression was increased in $\mathrm{HBV}^{+}$THLE-3 cells and HepG2.215 at both the mRNA (Fig. 1B) and protein levels (Fig. 1C), compared with that in HBV- THLE-3 and HepG2 cells, respectively.
$H B V$ induces cIAP2 expression through transactivation of the cIAP2 promoter. The THLE-3 cell line was used for subsequent experiments to determine whether HBV-induced cIAP2 expression was due to the transactivation of the cIAP2 promoter. Therefore, a firefly luciferase reporter gene plasmid under the control of the cIAP2 promoter, designated as $(-2,000 /+55)$ cIAP2-Luc was constructed, and the luciferase expression in response to $\mathrm{HBV}$ infection was determined. As shown in Fig. 2A, luciferase activity was markedly increased in a HBV infection dose-dependent manner. Serial 5' flanking region deletions were then created on the $(-2,000 /+55)$ cIAP2-Luc and their responses to HBV infection were also investigated. The results showed that $(-100 /+55)$ cIAP2-Luc 
A
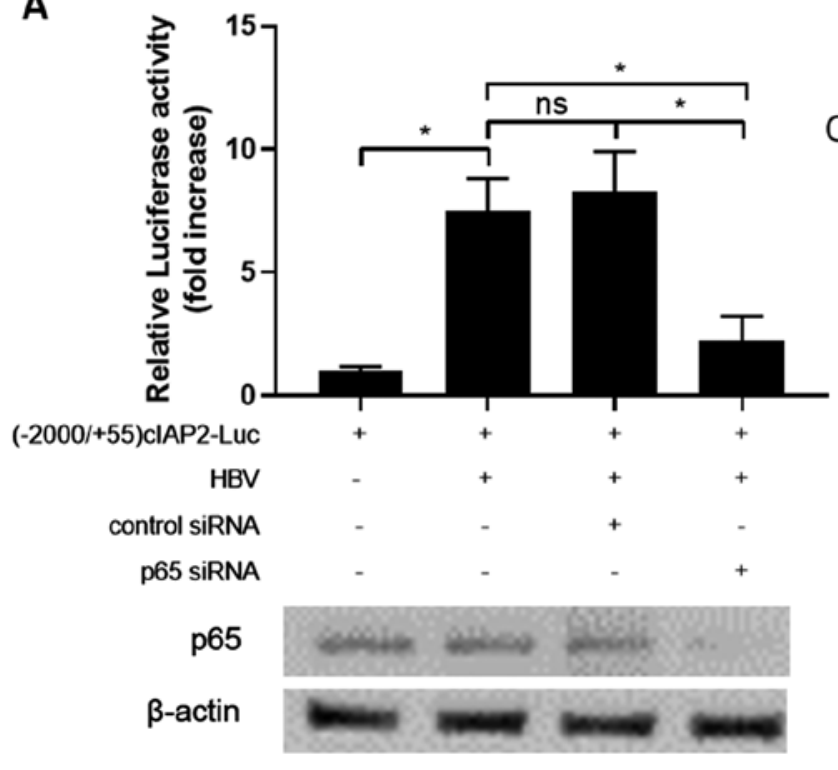

C

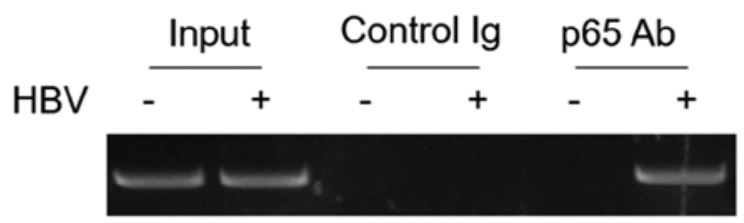

B
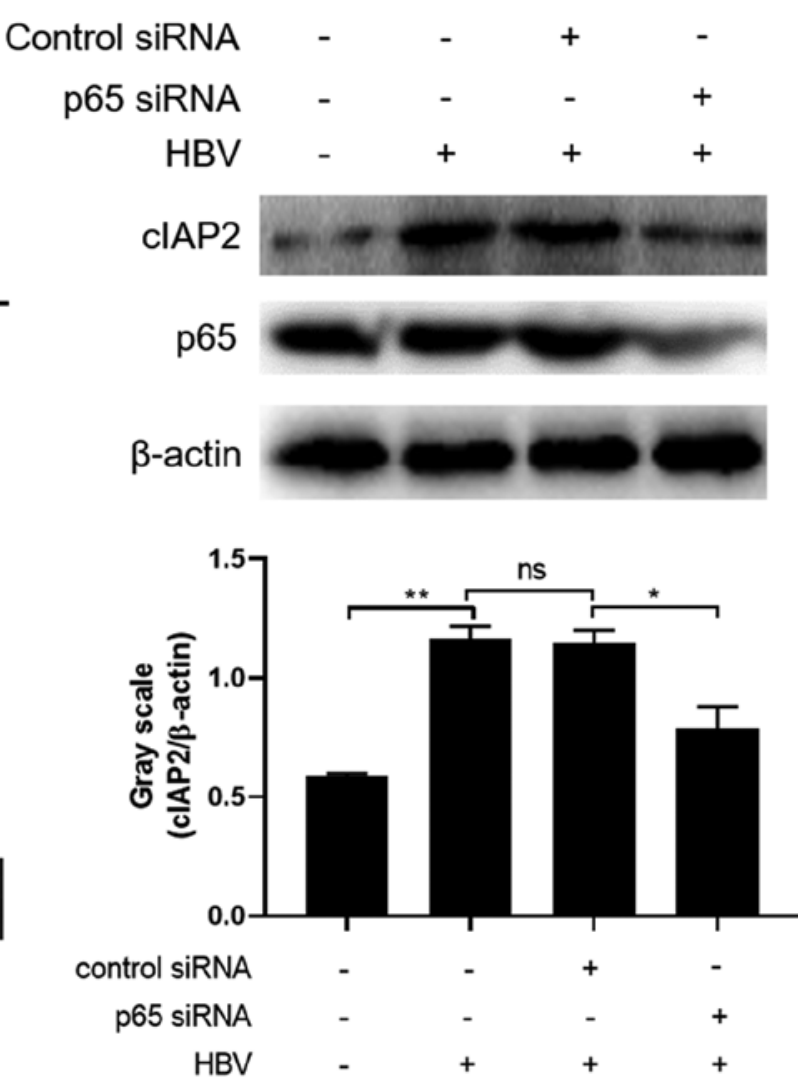

Figure 3. HBV-infection induces NF-кB binding onto cIAP2 promoter. (A) THLE-3 cells co-transfected with (-2,000/+55)cIAP2-Luc and p65 siRNA or control siRNA, were infected with HBV. Cells were lysed, and luciferase activity was measured $24 \mathrm{~h}$ after transfection. Data are presented as the mean \pm standard deviation of three independent experiments. "P<0.05. (B) THLE-3 cells transfected with p65 siRNA or control siRNA were infected with HBV and cIAP2 protein expression was determined using western blot analysis. ns, statistically not significant; ${ }^{*} \mathrm{P}<0.05 ;{ }^{* *} \mathrm{P}<0.01$. (C) Chromatin immunoprecipitation was performed following THLE-3 cells mock infected or infected with HBV, with either p65 or a control Ab, to pull down DNA segment containing the NF- $\mathrm{kB}$ binding site in the cIAP2 promoter. For western blot analysis, one representative result out of three is shown. cIAP2, cellular inhibitor of apoptosis protein 2; si, small interfering; HBV; hepatitis B virus; Ab, antibody; ns; not statistically significant.

variant had significantly lower luciferase activity, indicating that the deletion of the -250 to -100 nucleotide sequence abolished luciferase expression, and that this region is essential for cIAP2 promoter activation by HBV infection (Fig. 2B).

Previous bioinformatics analysis showed several transcription factor binding sites, including one AP1, three NF- $\mathrm{KB}$ sites and one IRF-1 site, in the region of $-250 \mathrm{nt}$ to $-100 \mathrm{nt}$ in the cIAP2 promoter sequence (32) (Fig. 2C). To further determine if one or more transcription factor binding sites may be involved in $\mathrm{HBV}$-induced cIAP2 promoter transactivation, mutations to these transcription binding sites were created and their activation by HBV infection was investigated. The data showed that only the mutation to the NF- $\mathrm{kB}$ binding site closest to the transcription start site (designated as NF- $\mathrm{KB}^{* * * *}$ ) completely abolished luciferase expression, while the other mutations did not show any reduction in signal (Fig. 2D). These data herein indicate that NF- $\mathrm{KB}^{* * *}$ is involved in the cIAP2 transactivation by HBV infection.

$H B V$ infection induces $N F-\kappa B$ binding onto cIAP2 promoter. Since $\mathrm{NF}-\mathrm{KB}^{* * *}$ is essential for $\mathrm{HBV}$ to transactivate cIAP2 promoter, it was investigated whether NF- $\mathrm{KB}$ could bind to cIAP2 promoter and activate cIAP2 transcription. At the luciferase reporter gene level, p65 siRNA knockdown significantly decreased luciferase expression, which was induced by HBV infection, comparing to control siRNA transfected group (Fig. 3A). Similar results were observed when cIAP2 protein level was determined in cells infected with HBV in the presence or absence of p65 siRNA (Fig. 3B). These data indicate that NF- $\mathrm{KB}$ is involved in $\mathrm{HBV}$-induced cIAP2 transcription and expression.

To further confirm that NF- $\mathrm{KB}$ binds to cIAP2 promoter, ChIP assay was performed with cells mock infected with medium or infected with HBV. As presented in Fig. 3C, p65 antibody pulled down cIAP2 promoter sequence only when cells were infected with $\mathrm{HBV}$, indicating that upon HBV infection, NF- $\kappa B$ could bind to cIAP2 promoter and may assist the transcription of this gene.

$H B V$ infection increases $N F-\kappa B$ phosphorylation and nuclear translocation. The aforementioned data revealed that NF- $\kappa \mathrm{B}$ responded to HBV infection and played an important role in HBV-induced cIAP2 elevation. Subsequently, it was further investigated whether HBV infection would change NF- $\kappa B$ expression and/or function. A plasmid with a firefly luciferase reporter gene under the control of NF- $\kappa \mathrm{B}$ p 65 promoter was constructed and its response to HBV infection was measured. As shown in Fig. 4A, HBV infection showed no apparent 
A

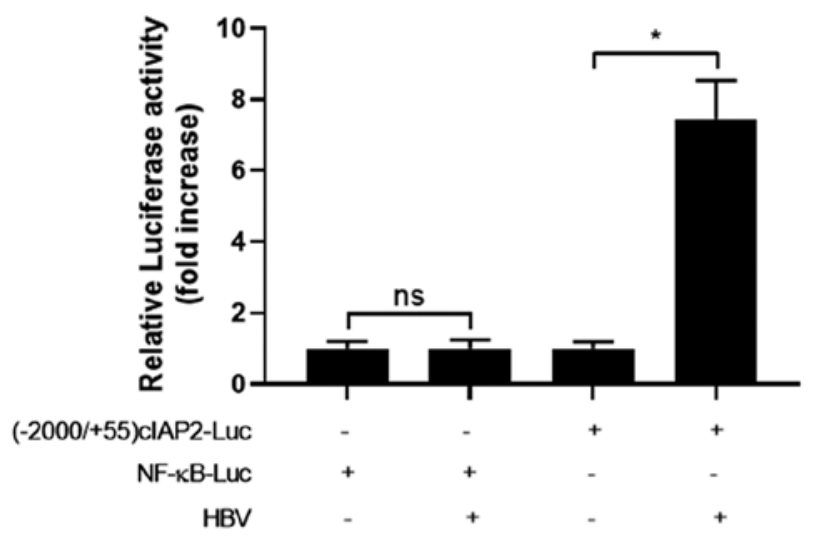

C
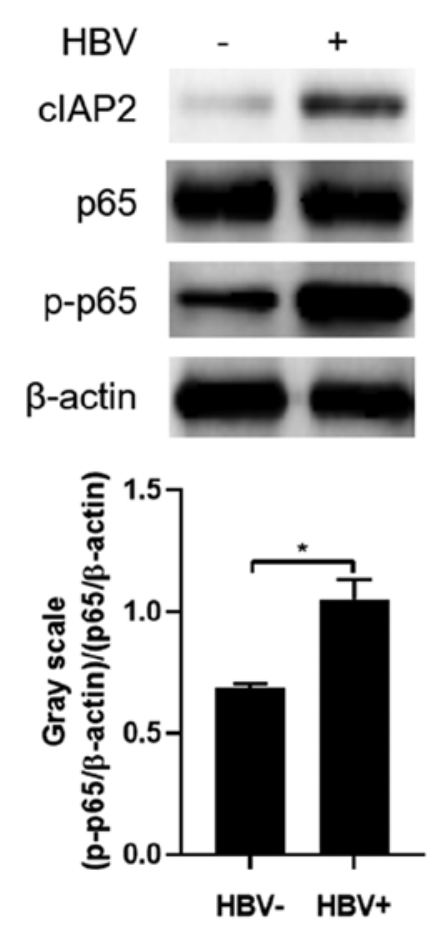

D
B

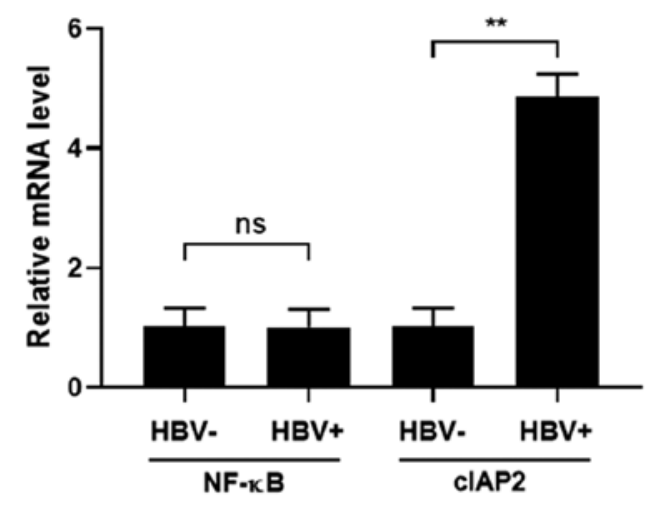
Cytoplasm Nucleus


Figure 4. HBV infection induces NF- $\mathrm{B}$ phosphorylation and nuclear translocation. THLE-3 cells transfected with (-2,000/+55)cIAP2-Luc or NF- $\kappa$ B-Luc were mock-infected or infected with HBV, and (A) luciferase activity (B) NF- $\mathrm{B}$ and cIAP2 mRNA levels, (C) cIAP2, p65 and p-p65 protein levels and (D) p65 protein expression in cytoplasmic and nuclear fractions were analyzed $24 \mathrm{~h}$ later. Data are presented as the mean \pm standard deviation of three independent experiments. For western blot analysis, one representative result out of three is shown. ${ }^{*} \mathrm{P}<0.05,{ }^{* *} \mathrm{P}<0.01$. cIAP2 cellular inhibitor of apoptosis protein 2 ; ns, not statistically significant; HBV; hepatits B virus; p, phosphorylated.

activation of the p65 promoter, as luciferase activity was not altered in THLE-3 cells transfected with NF- $\kappa \mathrm{B}-\mathrm{Luc}$ prior to and following $\mathrm{HBV}$ infection. As a control, HBV infection significantly enhanced luciferase activity in cells transfected with $(-2000 /+55)$ cIAP2-Luc, an indication of the activation of cIAP2 promoter. Similar results were observed when p65 mRNA level was determined. HBV infection did not enhance NF- $\kappa \mathrm{B}$ mRNA level, however did significantly enhance that of cIAP2 ( $<<0.01$; Fig. 4B). Western blot analysis of p65 expression further confirmed that HBV infection did not affect p65 expression, however, considerably increased phosphorylation of this protein was detected when cells were infected with

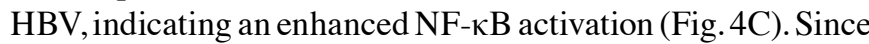
activated $\mathrm{NF}-\kappa \mathrm{B}$ needs to translocate from the cytoplasm into the nucleus in order to exert its function, it was subsequently determined whether a translocation of $\mathrm{NF}-\kappa \mathrm{B}$ was induced by HBV infection. As expected, upon HBV infection, there was a marked decrease of p65 in the cytoplasm while a significant increase in the nucleus was detected ( $\mathrm{P}<0.05$; Fig. 4D). Together, these data here indicate that HBV infection does not affect NF- $\mathrm{NB}$ expression but promotes its activation and translocation from the cytoplasm into the nucleus.

HBVinfection-inducedcIAP2 ismediated bythe PI3K/AKT/NF- $\kappa B$ signaling pathway. To further explore the signaling pathways HBV employs to increase cIAP2 expression, signaling pathway inhibitors specifically targeting NF- $\mathrm{B}, \mathrm{MAPKK}, \mathrm{PI} 3 \mathrm{~K}$ and $\mathrm{p} 38$ were analyzed for their ability to block HBV-infection induced cIAP2 transactivation. Of the inhibitors investigated, only NF- $\kappa$ B and PI3K pathway inhibitors significantly suppressed cIAP2 
A



C

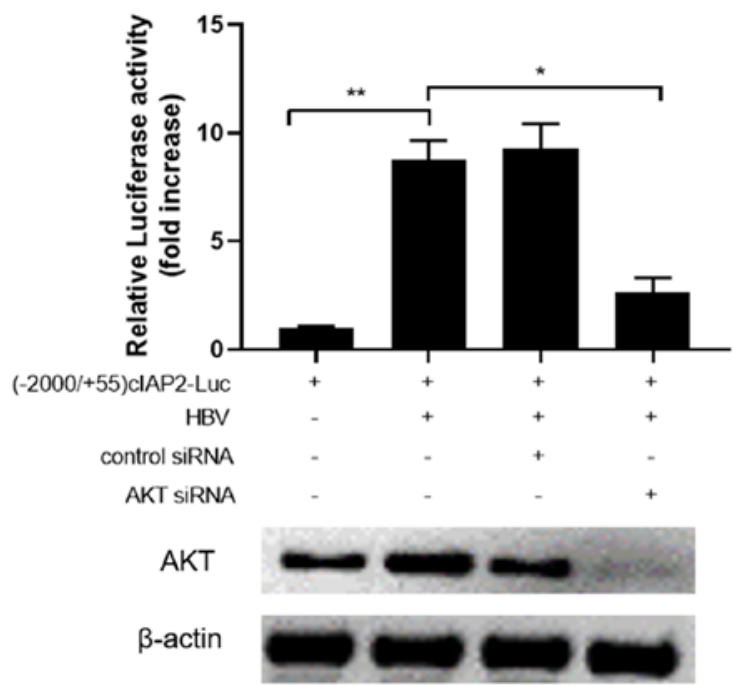

B

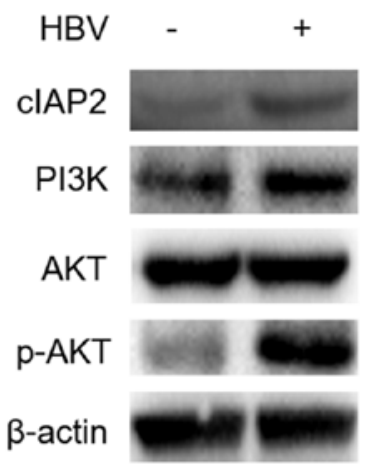

D

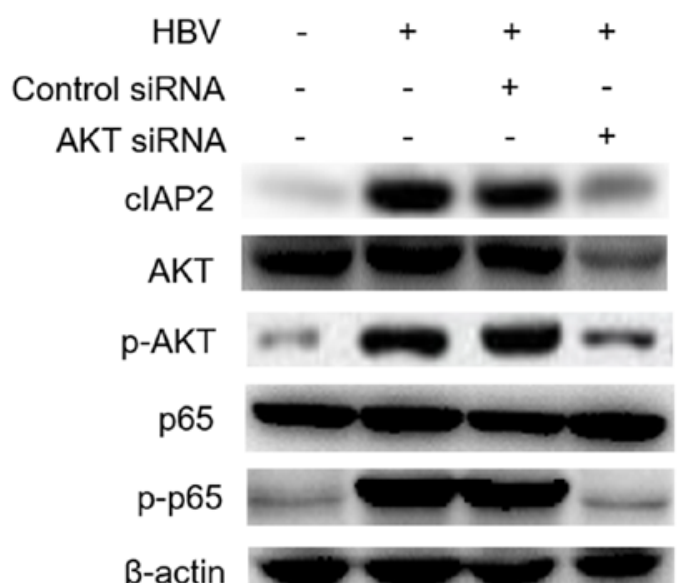

Figure 5. HBV induces cIAP2 expression by activating PI3K/AKT signaling pathway. (A) THLE-3 cells transfected with (-2,000/+55)cIAP2-Luc were mock-infected or infected with HBV, in the presence or absence of signaling pathway inhibitors. Cells were lysed, and luciferase activity was measured $24 \mathrm{~h}$ later. (B) THLE-3 cells were mock-infected or infected with HBV, then cIAP2, PI3K, AKT and p-AKT expression was determined using western blot analysis. (C) THLE-3 cells co-transfected with (-2,000/+55)cIAP2-Luc and AKT siRNA or control siRNA, were infected with HBV. Cells were lysed, and luciferase activity was measured $24 \mathrm{~h}$ later. (D) THLE-3 cells transfected with AKT siRNA or control siRNA were infected with HBV and cIAP2, AKT, p-AKT, NF- $\mathrm{kB}$ and $\mathrm{p}-\mathrm{NF}-\mathrm{kB}$ expression was determined using western blot analysis. For western blot analysis, one representative result out of three is shown. Data are presented as the mean \pm standard deviation of three independent experiments. ${ }^{*} \mathrm{P}<0.05 ;{ }^{* *} \mathrm{P}<0.01$. HBV; hepatits B virus; cIAP2 cellular inhibitor of apoptosis protein 2; si, small interfering; p, phosphorylated.

transactivation included by HBV infection (Fig. 5A). Further western blot analysis revealed that HBV infection did not affect PI3K and AKT expression, but markedly increased the p-AKT level (Fig. 5B). To further confirm the importance of AKT in $\mathrm{HBV}$-induced cIAP2 expression, HBV activation of cIAP2 promoter in the presence or absence of AKT siRNA was analyzed. The data showed that AKT-knockdown by siRNA significantly reduced the level of cIAP2 promoter activation induced by HBV infection (Fig. 5C). Western blot results further confirmed the involvement of AKT in HBV-induced cIAP2 expression, as AKT-knockdown reduced the level of cIAP2 and p-p65, which was enhanced by HBV infection (Fig. 5D).

\section{Discussion}

It has been well documented that chronic HBV infection has a role in liver cancer pathogenesis, however, mechanisms underlying HBV-induced liver cancer seem to be multifaceted and cannot be exhaustive $(10,20,21)$. Therefore, identifying new mechanisms is not only important for understanding the pathogenesis of this disease, but also beneficial for the development of new diagnostic and treatment targets. In the present study, it was identified that $\mathrm{HBV}$-infection can enhance anti-apoptotic protein cIAP2 expression by activating its promoter via the $\mathrm{PI} 3 \mathrm{~K} / \mathrm{AKT} / \mathrm{NF}-\kappa \mathrm{B}$ signaling pathway. These findings have proposed a novel mechanism underlying HBV-induced liver cancer and may offer valuable information for the development against liver cancer.

cIAP2 belongs to the IAP protein family, which is a highly conserved protein family that regulate cell survival, immunity, inflammation and cell division (22). cIAP2 and other members of this family are frequently dysregulated in numerous types of cancer, including colorectal cancer, lung cancer and prostate cancer, and high expression of this protein is also associated with poor outcome in these cancers (22-24). In liver cancer, to the best of our knowledge, the importance of cIAP2 has not been well 
studied. In the present study, it was revealed that cIAP2 is upregulated by HBV infection in both clinical tissues and cell lines. However, due to the limited number of clinical samples obtained, a more in-depth investigation on the relationship between cIAP2 expression and HBV-induced liver cancer severity and prognosis could not be performed. Further investigation with a higher number of clinical samples to further access this relationship would give a better understanding of cIAP2 in liver cancer and may also be beneficial for the evaluation of cIAP 2 as a diagnostic and/or treatment target.

Drug development targeting cIAP2 and other IAP family members, albeit in very limited number, has been studied at both the pre-clinical and clinical levels. Up to now, several strategies have been evaluated, including small chemical compounds, Smac mimetics and antisense oligonucleotides. For example, YM155, a novel molecule targeting and inhibiting IAP member survivin, has shown good anticancer activity against a variety of tumors including esophageal cancer and colorectal cancer in a Phase I clinical trial (30). Now this small molecule is being studied in combination with other anticancer treatment drugs in various cancer clinical studies $(31,32)$. Birinapant, a bivalent Smac mimetic targeting TNF receptor associated factor-2-associated cIAPs, is another anticancer drug targeting cIAPs that has shown good efficacy in suppressing tumor growth in a range of solid tumors, including esophageal, thymic and colorectal tumors, and lymphoma when used alone or in combination with other drugs, such as elrotnib and rituximab, in Phase I and II clinical studies (33-35). Since this study reveals cIAP2 is associated with $\mathrm{HBV}$-infection induced liver cancer, further investigation is required to explore the efficacy of IAP-targeting anticancer drugs on liver cancer treatment.

$\mathrm{HBV}$, a DNA virus with a $3.2 \mathrm{~kb}$ genome, contains four overlapping open reading frames coding for the surface (HBs), Core (HBc), X and the polymerase genes. Several viral genes have been identified as cancer related. Among them, $\mathrm{HBx}$ is the mostly studied one (13-16). HBx is associated with a wide range of cancer-related biological pathways, including the cell cycle, cell growth, apoptosis, inflammation, genome stability and metastasis $(36,37)$. HBs can also modulate inflammation and the cell cycle by various pathways, including downregulation of TLR9 and inhibition of interferon production, which can be contributors to liver cancer pathogenesis (38). Although still controversial, HBc can reportedly suppress cell apoptosis by downregulation of Fas, Fas ligand and TP53 (39). In the present study, the identification of one of more viral genes which may trigger cIAP2 upregulation was not determined. However, it would be of interest to investigate the viral components in cIAP2 expression, in a further study.

There are three subtypes of AKT proteins in humans (namely AKT1, 2 and 3) and the AKT antibody used in the present study could detect all three subtypes of AKT, therefore it was not possible to directly identify which subtype may play a major role. However, previous publications indicate that AKT1 is involved in cell survival pathways by inhibiting apoptotic processes $(40,41)$, AKT2 is an important molecule in insulin signaling pathway (42), and AKT3 with a less clear role is predominantly expressed in the brain (43). Therefore, it is likely that AKT1 was the subtype identified in the present study and might play a role in HBV-induced cIAP2 expression.
Taken together, the current study has identified that $\mathrm{HBV}$-infection can enhance anti-apoptotic protein cIAP2 expression by activating its promoter via the $\mathrm{PI} 3 \mathrm{~K} / \mathrm{AKT} / \mathrm{NF}-\kappa \mathrm{B}$ signaling pathway. These findings have proposed a novel mechanism underlying HBV-induced liver cancer and may offer valuable information for the development against liver cancer.

\section{Acknowledgements}

Not applicable.

\section{Funding}

No funding was received.

\section{Availability of data and materials}

The datasets used and/or analyzed during the current study are available from the corresponding author on reasonable request.

\section{Author's contributions}

JL and LC designed the experiments. JL, YZ, LH and HC performed the experiments. JC, YZ, LH, KH and JZ analyzed the data. JL wrote the paper. KH, JZ and LC checked and finalized the manuscript. All authors read and approved the final manuscript.

\section{Ethics approval and consent to participate}

All protocols involving human samples were reviewed and approved by the Ethical Review Board at The Affiliated Hospital of Jinggangshan University (Jiangxi, China; ref. JGSU-20170071), and written informed consent was provided from all the participating patients.

\section{Patient consent for publication}

Not applicable.

\section{Competing interests}

The authors declare that they have no competing interests.

\section{References}

1. Huang J, Ye X, Guan J, Chen B, Li Q, Zheng X, Liu L, Wang S, Ding Y, Ding Y and Chen L: Tiam1 is associated with hepatocellular carcinoma metastasis. Int J Cancer 132: 90-100, 2013.

2. Balogh J, Victor D III, Asham EH, Burroughs SG, Boktour M, Saharia A, Li X, Ghobrial RM and Monsour HP Jr: Hepatocellular carcinoma: A review. J Hepatocell Carcinoma 3: 41-53, 2016.

3. Ringelhan M, McKeating JA and Protzer U: Viral hepatitis and liver cancer. Philos Trans R Soc Lond B Biol Sci 372: 20160274 2017.

4. Fujiwara N, Friedman SL, Goossens N and Hoshida Y: Risk factors and prevention of hepatocellular carcinoma in the era of precision medicine. J Hepatol 68: 526-549, 2018.

5. Levrero M and Zucman-Rossi J: Mechanisms of HBV-induced hepatocellular carcinoma. J Hepatol 64: S84-S101, 2016.

6. Wang S, Chen N, Chen Y, Sun L, Li L and Liu H: Elevated GPC3 level promotes cell proliferation in liver cancer. Oncol Lett 16: 970-976, 2018. 
7. Tian $\mathrm{Y}$ and $\mathrm{Ou} \mathrm{JH}$ : Genetic and epigenetic alterations in hepatitis B virus-associated hepatocellular carcinoma. Virol Sin 30: 85-91, 2015.

8. Trepo C, Chan HL and Lok A: Hepatitis B virus infection. Lancet 384: 2053-2063, 2014.

9. Sung WK, Zheng H, Li S, Chen R, Liu X, Li Y, Lee NP, Lee WH, Ariyaratne PN, Tennakoon C, et al: Genome-wide survey of recurrent HBV integration in hepatocellular carcinoma. Nat Genet 44: 765-769, 2012.

10. Buendia MA and Neuveut C: Hepatocellular carcinoma. Cold Spring Harb Perspect Med 5: a021444, 2015.

11. Murakami Y, Saigo K, Takashima H, Minami M, Okanoue T, Bréchot $\mathrm{C}$ and Paterlini-Bréchot $\mathrm{P}$ : Large scaled analysis of hepatitis B virus (HBV) DNA integration in HBV related hepatocellular carcinomas. Gut 54: 1162-1168, 2005.

12. Lau CC, Sun T, Ching AK, He M, Li JW, Wong AM, Co NN, Chan AW, Li PS, Lung RW, et al: Viral-human chimeric transcript predisposes risk to liver cancer development and progression. Cancer Cell 25: 335-349, 2014.

13. Tropberger P, Mercier A, Robinson M, Zhong W, Ganem DE and Holdorf M: Mapping of histone modifications in episomal HBV cccDNA uncovers an unusual chromatin organization amenable to epigenetic manipulation. Proc Natl Acad Sci USA 112: E5715-E5724, 2015.

14. Ringelhan M, O'Connor T, Protzer U and Heikenwalder M: The direct and indirect roles of HBV in liver cancer: Prospective markers for HCC screening and potential therapeutic targets. J Pathol 235: 355-367, 2015.

15. Menolfi D, Delamarre A, Lengronne A, Pasero P and Branzei D: Essential roles of the Smc5/6 complex in replication through natural pausing sites and endogenous DNA damage tolerance. Mol Cell 60: 835-846, 2015.

16. Wang HC, Huang W, Lai MD and Su IJ: Hepatitis B virus pre-S mutants, endoplasmic reticulum stress and hepatocarcinogenesis. Cancer Sci 97: 683-688, 2006.

17. Weber A, Boege Y, Reisinger F and Heikenwälder M: Chronic liver inflammation and hepatocellular carcinoma: Persistence matters. Swiss Med Wkly 141: w13197, 2011.

18. Chao CC: Inhibition of apoptosis by oncogenic hepatitis B virus $\mathrm{X}$ protein: Implications for the treatment of hepatocellular carcinoma. World J Hepatol 8: 1061-1066, 2016.

19. Chang CS, Huang SM, Lin $\mathrm{HH}, \mathrm{Wu} \mathrm{CC}$ and Wang CJ: Different expression of apoptotic proteins between HBVinfected and non-HBV-infected hepatocellular carcinoma. Hepatogastroenterology 54: 2061-2068, 2007.

20. Fattovich G,Stroffolini T,Zagni I and Donato F: Hepatocellular carcinoma in cirrhosis: Incidence and risk factors. Gastroenterology 127: S35-S50, 2004

21. Sunami Y, Ringelhan M, Kokai E, Lu M, O'Connor T, Lorentzen A, Weber A, Rodewald AK, Müllhaupt B, Terracciano L, et al: Canonical NF- $\mathrm{KB}$ signaling in hepatocytes acts as a tumor-suppressor in hepatitis B virus surface antigen-driven hepatocellular carcinoma by controlling the unfolded protein response. Hepatology 63: 1592-1607, 2016.

22. Wang Q, Wang X and Evers BM: Induction of cIAP-2 in human colon cancer cells through PKC delta/NF-kappa B. J Biol Chem 278: 51091-51099, 2003.

23. Gill C, Dowling C, O'Neill AJ and Watson RW: Effects of cIAP-1, cIAP-2 and XIAP triple knockdown on prostate cancer cell susceptibility to apoptosis, cell survival and proliferation. Mol Cancer 8: 39, 2009.

24. Wu HH, Wu JY, Cheng YW, Chen CY, Lee MC, Goan YG and Lee H: cIAP2 upregulated by E6 oncoprotein via epidermal growth factor receptor/phosphatidylinositol 3-kinase/AKT pathway confers resistance to cisplatin in human papillomavirus 16/18-infected lung cancer. Clin Cancer Res 16: 5200-5210, 2010.

25. Miura K, Karasawa H and Sasaki I: cIAP2 as a therapeutic target in colorectal cancer and other malignancies. Expert Opin Ther Targets 13: 1333-1345, 2009.

26. Huang W, Hu K, Luo S, Zhang M, Li C, Jin W, Liu Y, Griffin GE, Shattock RJ and Hu Q: Herpes simplex virus type 2 infection of human epithelial cells induces CXCL9 expression and CD4 ${ }^{+}$ $\mathrm{T}$ cell migration via activation of $\mathrm{p} 38$-CCAAT/enhancer-binding protein- $\beta$ pathway. J Immunol 188: 6247-6257, 2012.

27. Yoneda M, Hyun J, Jakubski S, Saito S, Nakajima A, Schiff ER and Thomas E: Hepatitis B virus and DNA stimulation trigger a rapid innate immune response through NF-кB. J Immunol 197: 630-643, 2016
28. Mrani S, Chemin I, Menouar K, Guillaud O, Pradat P, Borghi G, Trabaud MA, Chevallier P, Chevallier M, Zoulim F and Trépo C: Occult HBV infection may represent a major risk factor of non-response to antiviral therapy of chronic hepatitis C. J Med Virol 79: 1075-1081, 2007.

29. Livak KJ and Schmittgen TD: Analysis of relative gene expression data using real-time quantitative PCR and the 2(-Delta Delta C(T)) method. Methods 25: 402-408, 2001.

30. Hu K, He S, Xiao J, Li M, Luo S, Zhang M and Hu Q: Interaction between herpesvirus entry mediator and HSV-2 glycoproteins mediates HIV-1 entry of HSV-2-infected epithelial cells. J Gen Virol 98: 2351-2361, 2017.

31. Liu D, Zhu Y, Pang J, Weng X, Feng X and Guo Y: Knockdown of long non-coding RNA MALAT1 inhibits growth and motility of human hepatoma cells via modulation of miR-195. J Cell Biochem 119: 1368-1380, 2018.

32. Hong SY, Yoon WH, Park JH, Kang SG, Ahn JH and Lee TH: Involvement of two NF-kappa B binding elements in tumor necrosis factor alpha-, CD40-, and epstein-barr virus latent membrane protein 1-mediated induction of the cellular inhibitor of apoptosis protein 2 gene. J Biol Chem 275: 18022-18028, 2000.

33. Satoh T, Okamoto I, Miyazaki M, Morinaga R, Tsuya A, Hasegawa Y, Terashima M, Ueda S, Fukuoka M, Ariyoshi Y, et al: Phase I study of YM155, a novel survivin suppressant, in patients with advanced solid tumors. Clin Cancer Res 15: 3872-3880, 2009.

34. Shimizu T, Nishio K, Sakai K, Hayashi H, Okamoto K, Takeda M, Iwasa T, Tanaka K, Aoyama K, Morishita M and Nakagawa K: Phase I study of YM155, selective survivin suppressant in combination with elrotnib in patients with EGFR-mutant advanced non-small cell lung cancer. J Clin Oncol 34: e20585, 2016.

35. Papadopoulos KP, Lopez-Jimenez J, Smith SE, Steinberg J, Keating A, Sasse C, Jie F and Thyss A: A multicenter phase II study of sepantronium bromide (YM155) plus rituximab in patients with relapsed aggressive B-cell Non-Hodgkin lymphoma. Leuk Lymphoma 57: 1848-1855, 2016.

36. Benetatos CA, Mitsuuchi Y, Burns JM, Neiman EM, Condon SM, Yu G, Seipel ME, Kapoor GS, Laporte MG, Rippin SR, et al: Birinapant (TL32711), a bivalent SMAC mimetic, targets TRAF2-associated cIAPs, abrogates TNF-induced NF- $\kappa$ B activation, and is active in patient-derived xenograft models. Mol Cancer Ther 13: 867-879, 2014.

37. Amaravadi RK, Schilder RJ, Martin LP, Levin M, Graham MA, Weng DE and Adjei AA: A phase I study of the SMAC-mimetic birinapant in adults with refractory solid tumors or lymphoma. Mol Cancer Ther 14: 2569-2575, 2015.

38. Crawford N, Salvucci M, Hellwig CT, Lincoln FA, Mooney RE, O'Connor CL, Prehn JH, Longley DB and Rehm M: Simulating and predicting cellular and in vivo responses of colon cancer to combined treatment with chemotherapy and IAP antagonist Birinapant/TL32711. Cell Death Differ 25: 1952-1966, 2018.

39. Wang SQ and Wu JG: Biological effects of HBV X protein on hepatocellular carcinogenesis in association with cellular factors. Virol Sin 23: 146-151, 2008.

40. Lee WY, Bachtiar M, Choo CCS and Lee CG: Comprehensive review of Hepatitis B Virus-associated hepatocellular carcinoma research through text mining and big data analytics. Biol Rev Camb Philos Soc 94: 353-367, 2019.

41. Li YW, Yang FC, Lu HQ and Zhang JS: Hepatocellular carcinoma and hepatitis B surface protein. World J Gastroenterol 22: 1943-1952, 2016.

42. Liu W, Lin YT, Yan XL, Ding YL, Wu YL, Chen WN and Lin X: Hepatitis B virus core protein inhibits Fas-mediated apoptosis of hepatoma cells via regulation of $\mathrm{mFas} / \mathrm{FasL}$ and $\mathrm{sFas}$ expression. FASEB J 29: 1113-1123, 2015.

43. Tuttle RL, Gill NS, Pugh W, Lee JP, Koeberlein B, Furth EE, Polonsky KS, Naji A and Birnbaum MJ: Regulation of pancreatic beta-cell growth and survival by the serine/threonine protein kinase Akt1/PKBalpha. Nat Med 7: 1133-1137, 2001. 